\title{
Application of surface plasmon resonance phenomenon for early detection and determination of the drug concentration for treating the relapses of malignant tumors
}

\author{
N.Ya. Gridina ${ }^{1}$, V.P. Maslov ${ }^{2}$ Yu.V. Ushenin ${ }^{2}$, V.D. Rozumenko ${ }^{1}$, A.N. Morozov ${ }^{1}$ \\ ${ }^{I}$ The State Institution “A.P. Romodanov Institute of Neurosurgery, NAMS of Ukraine”, \\ 04050 Kyiv, Ukraine \\ ${ }^{2}$ V. Lashkaryov Institute of Semiconductor Physics, NAS of Ukraine, 03680 Kyiv, Ukraine \\ E-mail: gridinanina@ukr.net
}

\begin{abstract}
One of promising directions in oncology is the development of methods for treatment of malignant tumors with account of mechanisms of their genesis and focused on correction of definite pathogenesis components, while being nontoxic for other organs and tissues. Investigated in this work was the possibility to use the phenomenon of surface plasmon resonance (SPR) for analysis of blood inherent to patients with glioma of different degrees of malignancy by studying the level of aggregation of blood cells. For this aim, we ascertained correlation between SPR characteristics and the condition of patient as well as choice of the drug efficient concentration. The works were performed being based on positive results preliminary obtained in experiments with lab rats, which were carried out in cooperation with the State Institution "A.P. Romodanov Institute of Neurosurgery, NAMS of Ukraine", and V. Lashkaryov Institute of Semiconductor Physics, NAS of Ukraine by using the device "Plasmon". It has been experimentally shown that, when using the chosen drug by treated patients, the signs of toxical action of verapamil hydrochloride are absent, and the life span is 10 months longer as compared with the group of patients that are not treated with this drug in low concentrations during the postoperative period.
\end{abstract}

Keywords: surface plasmon resonance, aggregation of blood cells, glioma, diagnostics, treatment.

https://doi.org/10.15407/spqeo23.01.85

PACS 73.20.Mf

Manuscript received 04.10.19; revised version received 24.12.19; accepted for publication 18.03.19; published online 23.03.19.

\section{Introduction}

One of the promising directions in oncology is elaboration of methods for treating the malignant tumors with account of mechanisms of their development, which are focused on correction of definite pathogenesis components and are not toxical for other organs and tissues. The blood is the internal medium in human organism, therefore, even small changes in its homeostatic characteristics have essential diagnostic and prognostic significance. In full, this can be related to the complex indices of fluidity and microrheologic characteristics inherent to peripheral blood cells. To the microrheologic indices of erythrocytes, one can relate their deformability and aggregation, the numerical characteristics of which are the indicators of organism condition in whole. To the main factors defining aggregation of erythrocytes, one can relate, first of all, the charge of their membranes. Lowering this charge increases aggregation of erythrocytes and is one of the main factors influencing their sedimentation [1].

It was shown in the recent time that any malignant process in the human organism is accompanied by tumorassociated inflammation (TAI) [2-5]. In our previous investigations, it was ascertained that TAI is practically absent in benign neoplasms, but arises and begins to progress when malignant tumors are available [6, 7]. It is clearly seen in the case of brain glioma progression, when this glioma transforms from a conditionally benign condition of the $2^{\text {nd }}$ degree into the condition of the $4^{\text {th }}$ degree of malignancy, which is characterized by fast development and results in the patient death for two years. In this case, malignant characteristics of tumors are tightly related with availability of TAI.

Thus, determination of the blood cell aggregation level that defines the $2^{\text {nd }}$ stage of inflammation process of any origin, including the tumor one, with the aim of early diagnostics of relapses in the growth of malignant tumor, 


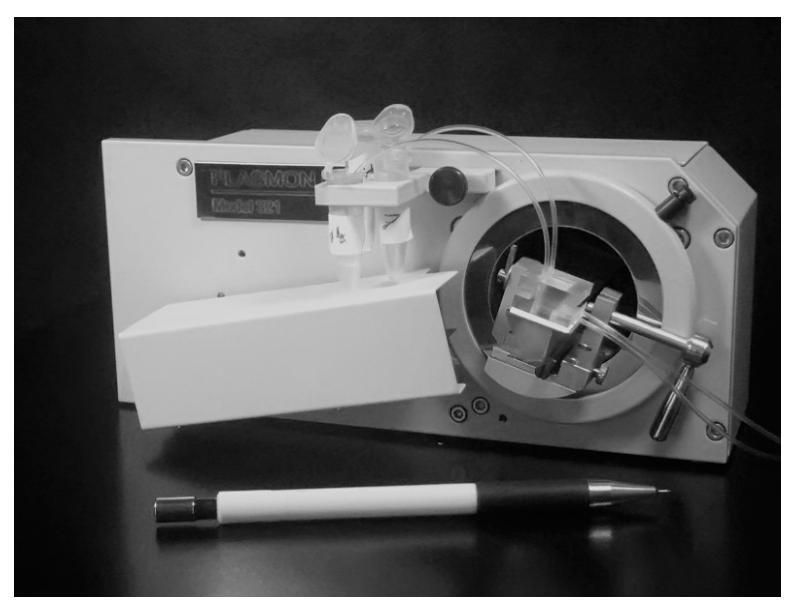

Fig. 1. External look of the device "Plasmon-6".

with the following correcting them by the individually selected concentrations of verapamil hydrochloride with the device "Plasmon", is a topical task. Innovation of this approach is that the sensors based on SPR enable to determine the blood cell aggregation level for a few minutes, without using any buffer systems and salt solutions, luminescent or radioactive lables, which allows obtaining objective results with blood cells. At the same time, using the calcium channel inhibitors (like to verapamil hydrochloride) enables to treat patients without toxical actions on the organism for a prolong time without interruption of treatment.

The aim of this work was to study the possibility of using the device "Plasmon" to detect blood cell aggregation for diagnosing and treating the patients with glioblastomas in the postoperative period.

\section{Biosensors, materials and methods of investigation}

Studying the initial processes of blood cell aggregation was performed using the device "Plasmon-6" designed and produced in the V. Lashkaryov Institute of Semiconductor Physics. This device in the real-time scale displays processes of blood cell aggregation [8-17].

The external look of device (Fig. 1) and its operation performances are adduced below.

Surface plasmon resonance is a unique optical surface sensing technique that is responsive to refractive index changes that occur within the vicinity of a sensor surface. Thus, SPR can be used to monitor any physical phenomenon that alters the refractive index at the surface and has grown into a versatile technique used in variety of applications. Of special interest is its potential for biosensing techniques.

The spectrometer "Plasmon" based on the SPR phenomenon enables to obtain information of optical properties inherent to the layer adjacent to the gold surface of the device sensor chip. Changes of the layer optical properties result in the shift of the SPR curve (SPR characteristic).

The thickness of layer, which is sensible for this spectrometer is close to $0.2 \mu \mathrm{m}$. At the same time, for example, the sizes of erythrocytes reach $6.2-8.2 \mu \mathrm{m}$. Therefore, the SPR characteristic of device depends both on the quantity of blood cells in the sample and on their mutual position ("coin columns"), which, in their turn, depend on the properties of membranes.

Earlier, using the SPR method researchers carried out investigations of reaction "antibody - antigen", but later there arise the works aimed at ascertaining the mechanisms of blood coagulation as well as other techniques. The method providing determination of the blood cell aggregation degree was not used by somebody and for the first time was developed by the authors [12].

The performed analysis of commonly adopted clinic characteristics of erythrocyte sedimentation rate (ESR) and quantitative composition of blood cells showed that in the case of brain gliomas these characteristics do not practically differ from those of normal condition (Table 2). Except the characteristics of total erythrocyte number, which with increasing the aggregation degree tend to group in the so-called "coin columns" that occupy a smaller substrate area for a larger amount of cells as compared to the normal erythrocytes of healthy persons. This fact lies in the background of the method for determination of the blood cell aggregation degree with SPR (Table 2).

As known, aggregation or agglutination of blood cells results in lowering the ratio of surface area inherent to cell particles to their volume. In this case, the total amount of cells can be larger, while the area of contact with the gold film can be less, which leads to the decreased SPR characteristics [12].

The adduced examples are indicative of a straight dependence between the degree of filling the sensor chip and SPR characteristics.

Blood erythrocytes (Figs 2A and 2D) are represented by the rounded lumps filling practically all the field of microscope.

In Fig. 2 ( $\mathrm{B}$ and $\mathrm{E}$ ), the erythrocytes have the external appearance resembling the coin columns typical for many pathologies, in particular, for tumors and inflammations as well as after addition of $3 \%$ solution of potassium chloride. This solution considerably enhances

Table 1. Performances of the devices of "Plasmon" series.

\begin{tabular}{|l|c|}
\hline Refractive index measurement range & $1.0-1.5$ \\
\hline $\begin{array}{l}\text { Detection limit of refractive index } \\
\text { variation }\end{array}$ & 0.00005 \\
\hline $\begin{array}{l}\text { Angle-of-incidence setting precision, } \\
\text { angular sec }\end{array}$ & 10 \\
\hline Maximum angular scan & $17^{\circ}$ \\
\hline $\begin{array}{l}\text { Maximum time resolution of kinetics } \\
\text { measurements, } \mathrm{s}\end{array}$ & $\leq 3$ \\
\hline Light source, GaAs laser, nm & $\pm 5 \mathrm{~V}$ \\
\hline Additional ADC input (optional) & $215 \times 130 \times 100$ \\
\hline $\begin{array}{l}\text { Overall dimensions of the } \\
\text { measurement unit, mm }\end{array}$ & $\mathrm{USB}$ \\
\hline Weight & $2.5 \mathrm{~kg}$ \\
\hline Computer connect & \\
\hline
\end{tabular}


Table 2. Clinic characteristics of the amount of blood cells for various neurosurgical pathologies.

\begin{tabular}{|l|c|c|c|}
\hline Diagnosis & $\begin{array}{c}\text { Erythrocytes, } \\
10^{12} / \mathrm{L}(n)\end{array}$ & $\begin{array}{c}\text { Leukocytes, } \\
10^{9} / \mathrm{L}(n)\end{array}$ & $\begin{array}{c}\text { Lymphocytes, } \\
10^{9} / \mathrm{L}(n)\end{array}$ \\
\hline Healthy & $4.73 \pm 0.33(9)$ & $5.59 \pm 1.32(9)$ & $2.26 \pm 0.44(9)$ \\
\hline Gliomas II & $5.14 \pm 0.59(19)$ & $8.46 \pm 3.68(19)$ & $2.04 \pm 0.52(18)$ \\
\hline Gliomas III & $5.00 \pm 0.60(33)$ & $8.60 \pm 3.58(37)$ & $2.12 \pm 0.85(35)$ \\
\hline Gliomas IV & $4.88 \pm 0.67(21)$ & $11.38 \pm 3.89(25)$ & $1.99 \pm 0.93(25)$ \\
\hline Metastases & $4.87 \pm 0.77(7)$ & $10.14 \pm 6.29(7)$ & $1.39 \pm 0.53(7)$ \\
\hline Craniocerebral injury & $4.31 \pm 0.49(8)$ & $7.81 \pm 2.59(9)$ & $1.81 \pm 0.57(8)$ \\
\hline Intervertebral hernias & $4.79 \pm 0.80(5)$ & $5.57 \pm 0.65(3)$ & $1.80 \pm 0.53(3)$ \\
\hline
\end{tabular}

Note. II, III, IV are the degrees of glioma malignancy; $n$ in brackets - amount of investigated patients.

Table 3. The life expectancy of patients treated with verapamil hydrochloride during the process of combined treatment of glioblastomas in the late postoperative period.

\begin{tabular}{|l|c|c|c|c|}
\hline Group & $\begin{array}{c}\text { Number of } \\
\text { patients }\end{array}$ & $\begin{array}{c}\text { Mean } \\
\text { (months) }\end{array}$ & $\begin{array}{c}\text { Standard deviation } \\
\text { (months) }\end{array}$ & $\begin{array}{c}\text { Median life span expected } \\
\text { (months) }\end{array}$ \\
\hline $\begin{array}{l}\text { Patients, treated } \\
\text { without verapamil }- \\
\text { hydrochloride }\end{array}$ & 32 & 8.47 & 1.02 & 7 \\
\hline $\begin{array}{l}\text { Patients, treated with } \\
\text { verapamil }- \\
\text { hydrochloride }\end{array}$ & 8 & 18.63 & 1.82 & 18 \\
\hline
\end{tabular}

aggregation of blood cells. As a result, the erythrocytes adjoin one to another by their biconcave surfaces more tightly, which promotes creation of coin columns. This process is reversible. But when adding the reagent anfi-D (usually used for determination of the blood group) to this solution, the blood cells agglutinate, and this process becomes irreversible.

As seen from Fig. 2 (B and E), the chip area covered with blood cells has many more empty parts as compared with the case of previous preparation deposited on the glass at the same blood volume (A and D). The fragments $\mathrm{C}$ and $\mathrm{F}$ represent the blood cells after treatment of them with the tsolyclone-A reagent used for agglutination of the cells related to the respective blood group. In this sample, the area of empty parts is larger than that of previous sample (B and E).

The obtained results show that the larger the area of parts non-filled with the blood cells, the higher the aggregation (agglutination) degree of blood cells and the lower the SPR characteristic value.

\section{The results of diagnostication and optimization of treating the patients with application of the spectrometer "Plasmon"}

The life expectancy of patients receiving a course of treatment with verapamil hydrochloride during a combined treatment of glioblastomas in the late postoperative period was shown in Table 3 and Fig. 3.
The initial SPR characteristics of 43 patients included to observation (11 treated with verapamil hydrochloride and 32 - non-treated) differed only slightly; it is indicative of adequacy in choosing the groups for investigation. To choose an optimal concentration of verapamil hydrochloride for this treatment, the blood was added with water solutions of verapamil after dilutions within the range 1:10 up to 1:100 000. 10-fold verapamil dilutions resulted in increasing the degree of aggregation, while the higher dilutions (10 000-fold), by contrast, caused lowering this aggregation. The verapamil concentration that corresponded to the strongest lowering the aggregation degree was then used for treating the patients with glioblastomas in the postoperative period. The optimal verapamil concentration for all the patients turned to be 10000 -fold lower than that commonly adopted. The patients took this preparation 3 times a day, continuously, without breaks, for life.

As the criteria of anti-tumor efficiency inherent to verapamil at low concentrations, we chose the life span of patients in the late postoperative period.

When using this preparation, the patients had no signs of verapamil toxic action on organism, and their life span was by 10 months longer than that of another group of patients non-treated with verapamil in low concentrations during the postoperative period.

The SPR characteristic values (corresponding to the blood cell aggregation degree) in the patients of both groups are represented in Figs 3 and 4. 

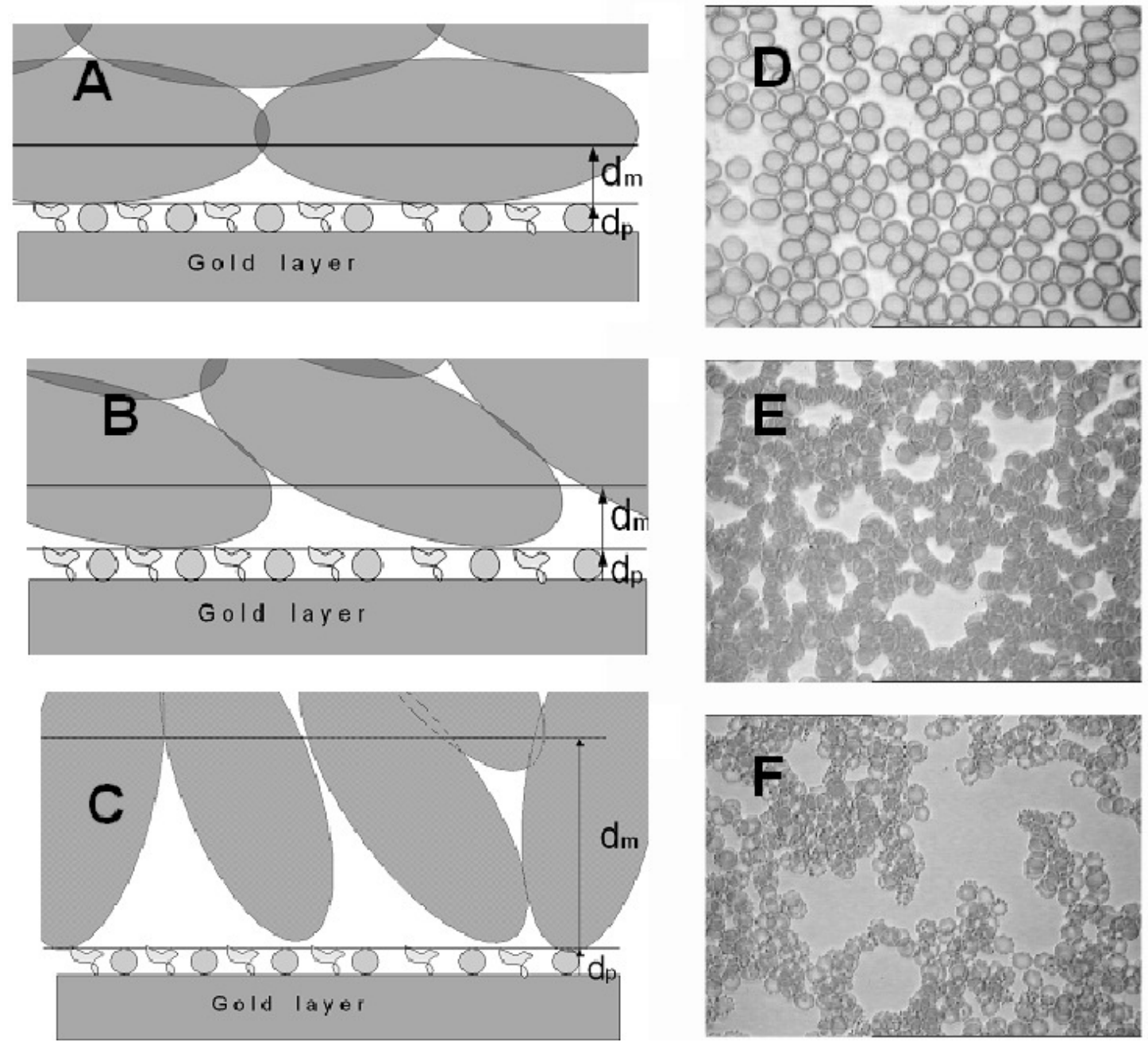

Fig. 2. Topology of blood cells (magnification $\times 200$ ) taken from: A and D - the healthy donor; B and E - erytrocytes arranged in the form of coin columns inherent to many kinds of pathologies or creating as a result of addition of $3 \%$ potassium chloride solution; $\mathrm{C}$ and $\mathrm{F}$ - blood cells after action of tsolyclone-A (diagnostic monoclone reagent) on them.

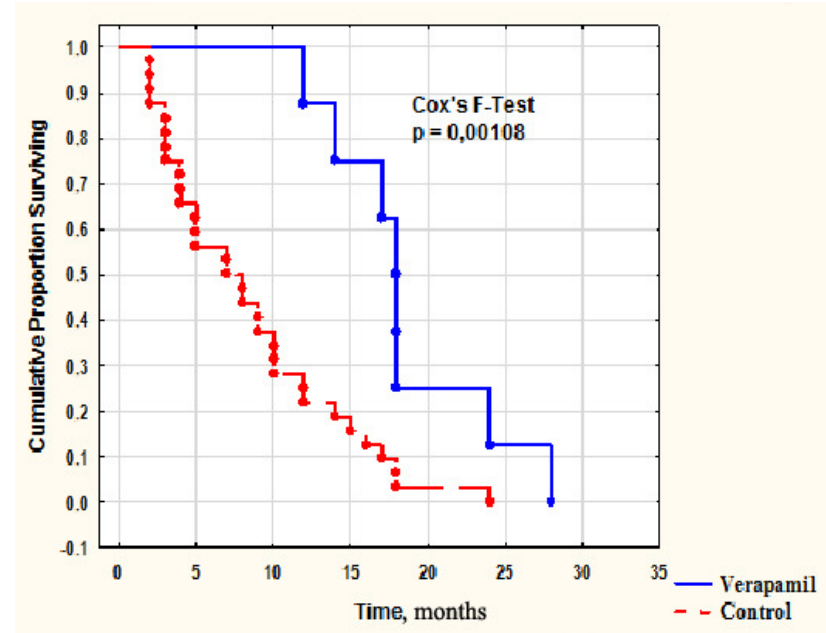

Fig. 3. Surviving data for the first ( 8 patients) and second $(32$ patients) groups of patients, who received and did not receive verapamil treatment, are significant by the Cox's F-test. The significance level is 0.00108 .

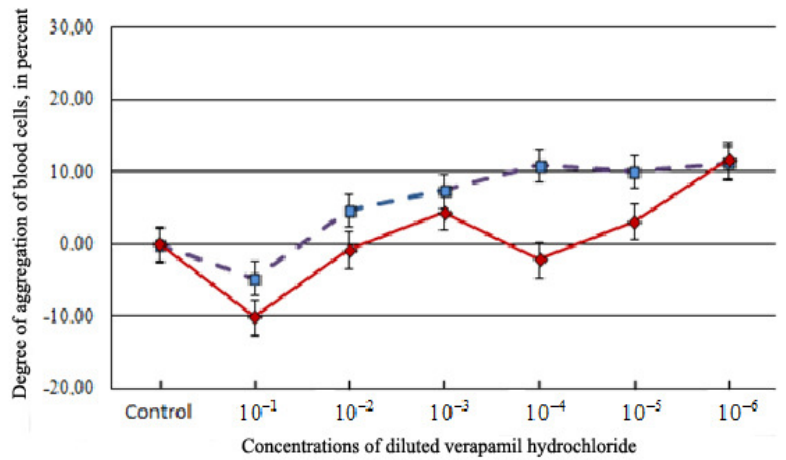

Concentrations of diluted verapamil hydrochloride; Control - without diluted.

Fig. 4. The ratio of data of blood cells aggregation under action of verapamil dilutions in patients with glioblastomas, treated (solid line) and non-treated with verapamil (dashed line). A comparison was made of SPR data in relation to the data of blood dilution with water $(20 \mu \mathrm{L}$ of water and $200 \mu \mathrm{L}$ of blood). 
As seen from Fig. 4, lowering the SPR characteristic values measured in the samples of blood cells after action of verapamil (10 000-fold water dilution) is similar to that in postoperative remission observed for patients with glioblastomas, which is reliably confirmed by the modern methods of visualization (magnetic resonance tomography and X-ray computer tomography). The increase of SPR characteristic values after action of 10000 -fold diluted verapamil was observed in patients with recurrent glioblastoma.

The dependence of blood cell aggregation degree on availability of the brain tumor was observed when adding verapamil into the blood, if its concentration corresponded to 10000 -fold dilution (concentration 10-4). In this case, the absence of relapses coincides with lowering the SPR values. It is also typical for benign as well as conditionally benign tumors, such as meningiomas or gliomas with malignancy of the second degree $[18,19]$.

The obtained results agree with the general tendencies, namely: one of the pathogenetic approaches in oncology is to apply action directed on lowering the effects of tumor-associated inflammation that forms tumor microenvironment promoting the tumor growth or acceleration of relapses occurrence and creation of metastases. Using the methods aimed at inhibition of TAI in the postoperative period acquires considerable interest within the framework of possible prophylaxis of the prolonged glioma growth. Most of anti-tumor drugs possess a number of side effects and cannot be recommended for long-term using them by patients with malignant tumors. Inhibition of TAI by application of the calcium channel inhibitor verapamil promoted the slowing-down of the glioma relapses occurrence without any toxical actions on organism during long-term application. However, with account of the membranemodifying action of calcium channel blockers, their concentration gradient is of essential importance. Consequently, to choose an optimal anti-tumor effect of the verapamil inhibitor (defined by breaking the TAI), in experiments it was necessary to choose its concentration in vitro with the following application of these results in treatment of patients to prolong their life span and to improve quality of life.

Thus, the results of using this innovation approach for breaking the glioma growth in patients coincide with those obtained earlier in experiments with lab rats carrying transplantable glioma (strain 101.8, analog of human glioblastoma) and are fully confirmed by clinical tests.

\section{Conclusion}

The results of investigations performed with patients at the A.P. Romodanov Neurosurgery Institute, National Academy of Medical Sciences of Ukraine (Kyiv, Ukraine) have shown a high efficiency of applying the method based on using the device "Plasmon" for early diagnostics and treatment of relapses inherent to malignant tumors (e.g., glioblastomas). This express method provides determination of blood cells aggregation characteristics within several minutes.

When using this preparation, the patients had no signs of verapamil toxic action on organism, and their life span was by 10 months longer than that of another group of patients non-treated with verapamil hydrochloride in low concentrations during the postoperative period.

\section{References}

1. Voyeikov V.L. Physico-chemical and physiological aspects of erythrocyte sedimentation rate. Uspekhi fiziologicheskikh nauk. 1998. 29, No 4. P. 55-73 (in Russian).

2. Luchnik A.N. A common link in the mechanism of self-maintenance of malignant growth: the syndrome of the nonhealing wound. Ontogenesis. 2000. 31, No 3. P. 227-231 (in Russian).

3. Schwarzburd P.M. Chronic inflammation increases risk of epithelial neoplasia by inducing precancerous microenvironment: an evaluation of pathways of disregulation. Voprosy Onkologii. 2006. 52, No 2. P. 137-144 (in Russian).

4. Mantovani A., Allavena P., Sica A., Balkwill F. Cancer-related inflammation. Nature. 2008. 454 (7203). P. 436-444. https://doi.org/10.1038/nature07205.

5. Whiteside T.L. The tumor microenvironment and its role in promoting tumor growth. Oncogene. 2008. 27, No 45. P. 5904-5912. https://doi.org/10.1038/onc.2008.271.

6. Gridina N.Ya. Utilizing SPR as a novel technique to measure cell aggregation for ketamine treated brain gliomas. Cancer and Oncology Res. 2013. 1, No 1. P. 1-5. https://doi.org/10.13189/cor.2013.010101.

7. Gridina N.Ya., Ushenin Yu.V., Maslov V.P. Tumorassociated Inflammations and Brain Gliomas. Lambert Academic Publishing, Saarbrücken, 2013.

8. Dorozhinskyi G.V., Maslov V.P., Ushenin Yu.V. Sensor Devices Based on Surface Plasmon Resonance. Kyiv: National Technical University of Ukraine "KPI", 2016 (in Ukrainian).

9. Bondeson K., Frostell-Karlsson A., Fagerstam L., and Magnusson G. Lactose repressor-operator DNA interactions: Kinetic analysis by a surface plasmon resonance biosensor. Analyt. Biochem. 1993. 214. P. 245-251. https://doi.org/10.1006/abio.1993.1484.

10. Chegel V., Shirshov Yu., Avilov S. et al. A novel aldehyde dextran sulfonate matrix for affinity biosensors. J. Biochem. Biophys. Methods. 2002. 50. P. 201-216. https://doi.org/10.1016/s0165-022x(01)00197-x.

11. Gaus K., Hall E.A.H. Surface plasmon resonance sensor for heparin measurements in blood plasma. Biosensors \& Bioelectronics. 1998. 13, No 12. P. 1307-1313. https://doi.org/10.1016/S0956-5663(98)00094-3.

12. Gridina N., Dorozinsky G., Khristosenko R. et al. Surface plasmon resonance biosensor. Sensors \& Transducers. 2013. 149, Issue 2. P. 60-68. 
13. Hansson K.M., Vikinge T.P., Ranby M. et al. Surface plasmon resonance (SPR) analysis of coagulation in whole blood with application in prothrombin time assay. Biosensors \& Bioelectronics. 1999. 14, No 8-9. P. 671-682. https://doi.org/10.1016/s0956-5663(99)00050-0.

14. Kambhampati D.K., Knoll W. Surface-plasmon optical techniques. Current Opinion in Colloid \& Interface Science. 1999. 4, No 4. P. 273-280. https://doi.org/10.1016/S1359-0294(99)90008-0.

15. Liedberg B., Nylander C., Lundstrom I. Biosensing with surface plasmon resonance - how it all started. Biosensors \& Bioelectronics. 1995. 10, No 8. P. 110. https://doi.org/10.1016/0956-5663(95)96965-2.

16. Piscevic D., Lawall R., Veith M., Liley M., Okahata Y., Knoll W. Oligonucleotide hybridization observed by surface plasmon optical techniques. Appl. Surf. Sci. 1995. 90, No 4. P. 425-436. https://doi.org/10.1016/0169-4332(95)00171-9.

17. Rengevich O.V., Shirshov Y.M., Ushenin Y.V., Beketov A.G. Separate determination of thickness and optical parameters by surface plasmon resonance: accuracy consideration. Semiconductor Physics, Quantum Electronics and Optoelectronics. 1999. 2, No 2. P. 28-35.

18. Gridina N.Ya., Shvachko L.P., Draguntsova N.G. Tumor-associated inflammation mechanisms correction by verapamil at brain gliomas progression. European Journal of Pharmaceutical and Medical Research (EJPMR). 2016. 3, No 8. P. 73-78.

https://www.ejpmr.com/admin/assets/article_issue/ 1469854979.pdf.

19. Gridina N.Ya., Maslov V.P., Kotovsky V.Y., Draguntsova N.G. Peculiarities of the spectrum of chromosome aberrations in the peripheral blood lymphocytes in cases of brain gliomas and their correction with verapamil and ketamine. Scholar Journal of Applied Medical Sciences (SJAMS). 2015 Sep. 3(6A). P. 2156-2160.

http://saspublisher.com/wp-content/uploads/ 2015/09/SJAMS-36A-2156-2160.pdf.

\section{Authors and CV}

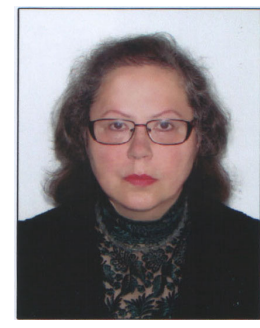

Nina Gridina, Candidate of Medical Sciences, Leading Researcher at the A.P. Romodanov Neurosurgery Institute, NAMS of Ukraine, Head of the laboratory of experimental neurosurgery. The main directions of her work are the study of mechanisms of malignant progression of gliomas of the brain and methods for their correction in experiment and in clinical studies. She is the author of 2 monographs, more than 200 scientific articles and patents.

ORCID: https://orcid.org/0000-0003-1137-8212

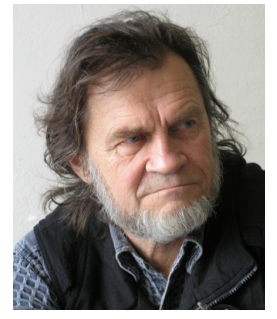

Yurii Ushenin got his degree in Vision and spectroscopy at Taras Shevchenko National University of Kyiv in 1971. Since 1973 he worked at the Institute of Semiconductor Physics, NAS of Ukraine as an engineer and senior researcher (since 1992 up to now). His area of expertise includes systems of collection and data processing, software design (Pascal, Delphi) and optical devices including SPR and planar semiconducting interferometer.

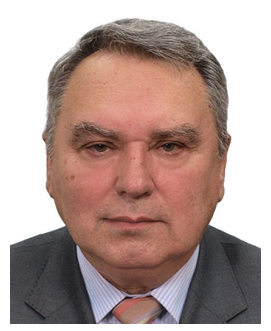

Prof. Volodymyr Maslov, Doctor of Materials Science, Head of the Department of physics and technological basics of sensor materials at the V. Lashkaryov Institute of Semiconductor Physics. Honored inventor of Ukraine. Author of more than 156 publications and more than 400 patents of Ukraine and USSR author's certificates. His research interests include several topics of optical engineering and physical behavior of functional materials as well as phenomena of surface plasmon resonance, with application of it in medicine and ecology.

ORCID: https://orcid.org/0000-0001-7795-6156

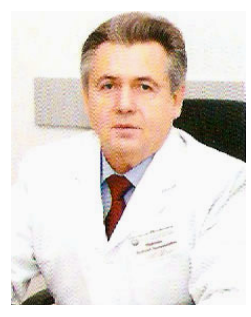

Prof. Anatoly Morozov, Doctor of Medical Sciences (2000), Professor (2002), Honored Doctor of Ukraine (1994), Head Doctor at the A.P. Romodanov Neurosurgery Institute, NAMS of Ukraine, scientific consultant of the Department of Experimental Neurosurgery and Clinical

Pharmacology, chairman of the commission for coordination and regulatory support of clinical trials under the Presidium of the National Academy of Medical Sciences of Ukraine (since 2015). The highest qualification categories in neurosurgery and in the organization and management of health care. His research interests include neurotraumatology, neurooncology, social hygiene, healthcare, pharmacology, and drug standardization.

ORCID: https:orcid.org/0000-0001-7092-4813

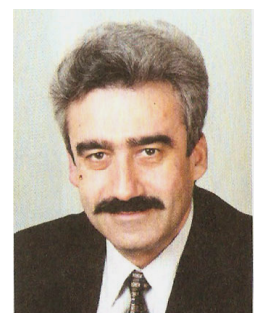

Prof. Vladymyr Rozumenko, Doctor of Medical Sciences, Professor, Head of the Department of Intracerebral Tumors at the A.P. Romodanov Neurosurgery Institute, NAMS of Ukraine, Honored Doctor of Ukraine. The main areas of scientific activity: development of new

highly effective methods of surgical interventions for tumors of functionally significant parts of the brain and tumors of deep localization using neuronavigation systems and microsurgical, endoscopic and laser technologies. ORCID: https://orcid.org/0000-0002-8774-6942 